\title{
Analysis of Sequence-Dependent Interactions Between Transient Calcium and Transmitter Stimuli in Activating Adenylyl Cyclase in Aplysia: Possible Contribution to CS-US Sequence Requirement During Conditioning
}

Thomas W. Abrams, ${ }^{1}$ Yoram Yovell, ${ }^{2}$ Chiadi U. Onyike, Jonathan E. Cohen, and Hugh E. Jarrard

${ }^{1}$ Departments of Pharmacology and Anesthesiology

University of Maryland School of Medicine

Baltimore, Maryland 21201-1559

${ }^{2}$ Columbia University College of Physicians and Surgeons

Department of Neuroscience

New York State Psychiatric Institute

New York, New York 10032

\section{Abstract}

An important recent insight in a number of neurobiological systems is that during learning, individual dually regulated proteins with associative properties function as critical sites of stimulus convergence. During conditioning in Aplysia, the $\mathrm{Ca}^{2+} /$ calmodulin-sensitive adenylyl cyclase (AC) in mechanosensory neurons serves as a molecular site of interaction between $\mathrm{Ca}^{2+}$ and serotonin [5-hydroxytryptamine (5-HT)] - two signals that represent the CS and $U S$ in these cells. Conditioning requires that the CS and US be paired within a narrow time window and in the appropriate sequence. AC shows an analogous sequence preference: It is more effectively activated when a pulse of $\mathrm{Ca}^{2+}$ precedes a pulse of 5-HT than when the 5-HT precedes $\mathrm{Ca}^{2+}$. One mechanism that contributes to this sequence preference is that $\mathrm{Ca}^{2+} /$ calmodulin binding to $\mathrm{AC}$ accelerates the rate of $\mathrm{AC}$ activation by receptor- $G_{\mathbf{s}}$. We have identified two additional properties of $\mathrm{AC}$ activation that would cause pairing with $\mathrm{Ca}^{2+}$

${ }^{1}$ Corresponding author. preceding 5-HT to be more effective than simultaneous pairing or pairing with the reciprocal sequence: (1) Activation of Aplysia AC by a $\mathrm{Ca}^{2+}$ pulse rose with a delay compared with activation by a 5-HT pulse. (2) A late pulse of $\mathrm{Ca}^{2+}$, which arrived after 5-HT, acted, via calmodulin, to accelerate the decay of AC activation by receptor- $G_{\mathbf{s}}$. Together, these activation properties of $\mathrm{AC}$ may contribute to the $C S-U S$ sequence requirement of classical conditioning.

\section{Introduction}

Through experience, animals learn relationships between stimuli or events in their environment or between these external events and their own behavior. A fundamental goal of the study of learning in simple neural systems is to identify general molecular mechanisms relevant to various types of learning in diverse species. A number of studies have suggested that during simple forms of associative learning, dually regulated proteins serve as the locus at which inputs from multiple stimuli or behaviors converge. According to this proposal, these proteins, such as the NMDA receptor (Collingridge 1987; Madison et al. 1991; Davis et al. 1992; Tsien et al. 1996) and the $\mathrm{Ca}^{2+} /$

LEARNING \& MEMORY 4:496-509 @ 1998 by Cold Spring Harbor Laboratory Press ISSN1072-0502/98 \$5.00

$$
\begin{array}{lllllllllllllllll}
\hline & A & R & N & I & N & G & \bigotimes_{496} & M & E & M & O & R & Y
\end{array}
$$


calmodulin-sensitive adenylyl cyclase (AC) (Abrams and Kandel 1988), serve an associative role: When two stimuli are paired with the appropriate temporal relationship, the protein responds to the pairing by triggering a second-messenger cascade that initiates alterations of neuronal properties. The type I and type VIII forms of AC, which are stimulated by $\mathrm{Ca}^{2+}$ via calmodulin (CaM), are expressed at relatively high levels in regions of mammalian brain believed to be involved in learning (Xia et al. 1991; Cali et al. 1994). Moreover, genetic deletion of $\mathrm{Ca}^{2+} /$ CaM-sensitive AC in Drosopbila (Dudai and Zvi 1984; Livingstone et al. 1984; Livingstone 1985; Levin et al. 1992) or mice (Wu et al. 1995) is associated with learning deficits.

Evidence that $\mathrm{Ca}^{2+} / \mathrm{CaM}$-sensitive $\mathrm{AC}$ has an associative function comes from cellular studies of associative synaptic plasticity in Aplysia. During conditioning of the defensive gill and siphon withdrawal reflex of Aplysia, there is an associative enhancement of the synaptic connections from the siphon sensory neurons, which mediate the input from the conditioned stimulus (CS), to interneurons and motoneurons that produce the withdrawal response. During this associative facilitation of the sensory neuron synapses, activity of the sensory neurons, which is triggered by the CS, is temporally paired with facilitatory transmitter, which is released by the unconditioned stimulus (US) (Hawkins et al. 1983; Walters and Byrne 1983; Abrams 1985). One important site of interaction between sensory neuron activity and facilitatory transmitter is the $\mathrm{Ca}^{2+} / \mathrm{CaM}$-sensitive $\mathrm{AC}$. When $\mathrm{Ca}^{2+}$ influx, which accompanies sensory neuron activity, is paired with facilitatory transmitter, there is a greater increase in cAMP levels than that produced by facilitatory transmitter alone (Ocorr et al. 1985). Elevations in CAMP within the sensory neurons initiate both short-term and long-term facilitation of their synaptic connections (Brunelli et al. 1976; Braha et al. 1990; Dash et al. 1990; Goldsmith and Abrams 1991, 1992; Ghirardi et al. 1992; Hochner and Kandel 1992; Klein 1993). Other cAMP-independent processes, including Hebbian plasticity, may also contribute to associative enhancement of transmitter release at these synapses (Murphy and Glanzman 1996, 1997); however, Abrams and Galun (T.W. Abrams and J.E. Galun, unpubl.) and Bao et al. (1998) have found that presynaptic cAMP-dependent phosphorylation plays a necessary role in associative synaptic facilitation.

Generally, in classical conditioning, an animal learns to associate the CS and US when the two stimuli are temporally paired during training so that the CS predicts the occurrence of the US. Most forms of conditioning show a sequence requirement in which the animal only learns the associative relationship if the CS begins before the US (Hearst 1988; Rescorla 1988). Conditioning of the defensive withdrawal reflex in Aplysia exhibits a number of features typical of mammalian conditioning paradigms, including the CS-US sequence requirement (Hawkins et al. 1986; Colwill et al. 1988). Activity-dependent facilitation displays a parallel sensitivity to the sequence of paired cellular events; optimal facilitation occurs when activity and $\mathrm{Ca}^{2+}$ influx, triggered by the $\mathrm{CS}$, precedes facilitatory transmitter, which is released by the US (Clark et al. 1994).

If the $\mathrm{Ca}^{2+} / \mathrm{CaM}$-sensitive $\mathrm{AC}$ serves as a coincidence detector during classical conditioning, one would expect that activation of this enzyme might also show an analogous sequence requirement. Yovell and Abrams (1992) explored whether activation of the $\mathrm{Ca}^{2+} / \mathrm{CaM}$-sensitive $\mathrm{AC}$ is affected by the order in which paired stimuli arrive. They found that although this enzyme is activated by both $\mathrm{Ca}^{2+}$ and facilitatory transmitter, the dual activation is not synergistic under normal steady-state assay conditions, where the two activating stimuli are present for the duration of the assay. However, perfused membrane experiments, in which the neural membranes are retained on a filter and exposed transiently to activating stimuli, revealed that $\mathrm{AC}$ shows the predicted sequence preference analogous to the sequence requirements of the conditioning and the associative synaptic plasticity: $\mathrm{Ca}^{2+}$ preceding transmitter gave more powerful activation than $\mathrm{Ca}^{2+}$ following transmitter or than transmitter without $\mathrm{Ca}^{2+}$ (Yovell and Abrams 1992). Although the mechanism of this sequence effect was not definitively identified, comparisons of the rising phase of the activation curve suggested that a prepulse of $\mathrm{Ca}^{2+}$ may increase the rate of activation by transmitter. In Aplysia neural membranes, as in most other systems, neurotransmitter receptors stimulate AC via a guanine nucleotide-binding stimulatory $\mathrm{G}$ protein, $\mathrm{G}_{\mathrm{s}}$ (Vogel 1989; Abrams et al. 1991). Because we knew that $\mathrm{Ca}^{2+}$ / CaM binds to AC (Yeager et al. 1985; Eliot et al. 1989), we hypothesized that this binding might induce a conformational change in AC that accelerates activation of $A C$ by receptor- $G_{s}$.

In the present study we have identified two additional characteristics of activation of Aplysia neural $\mathrm{AC}$ by $\mathrm{Ca}^{2+}$ and 5-hydroxytryptamine (5-HT)

$$
\text { n....... 国 }
$$


that would contribute to the observed sequence preference. Comparison of the time courses of AC activation by transient $5-\mathrm{HT}$ and $\mathrm{Ca}^{2+}$ stimuli revealed that activation by a $\mathrm{Ca}^{2+}$ pulse exhibits a small delay, such that interactions between the two stimulus pulses should be temporally coincident if the $\mathrm{Ca}^{2+}$ pulse begins first. Second, we observed that a transient $\mathrm{Ca}^{2+}$ stimulus that follows a 5-HT stimulus, as occurs with backward pairing, actually accelerates the decay of AC stimulation by transmitter; thus, a late pulse of $\mathrm{Ca}^{2+}$ has an inhibitory effect on overall $\mathrm{AC}$ activation.

\section{Materials and Methods}

\section{PREPARATION OF MEMBRANES}

Aplysia californica, weighing 100-200 grams, were obtained from Alacrity (Redondo Beach, CA) or Marinus, Inc. (Long Beach, CA). For each experiment, six animals were anesthetized by injection of isotonic $\mathrm{MgCl}_{2}$, and abdominal, cerebral, and pleural-pedal ganglia were removed. The ganglia were trimmed to reduce non-neural tissue (i.e., sheath) and then homogenized in a glass-glass homogenizer in $\sim 0.4 \mathrm{ml}$ per CNS of homogenization buffer [ $50 \mathrm{~mm}$ K-HEPES at $\mathrm{pH} 7.6,75 \mathrm{~mm} \mathrm{KCl}, 3 \mathrm{~mm}$ EGTA, $1 \mathrm{~mm}$ dithiothreitol (DTT), and protease inhibitors ( $1 \mathrm{~mm}$ benzamidine, $10 \mu \mathrm{g} / \mathrm{ml}$ of leupeptin, $10 \mu \mathrm{g} / \mathrm{ml}$ of aprotinin, and $25 \mu \mathrm{m}$ p-nitrophenyl-p'-guanidinobenzoate hydrochloride]. Any residual pieces of sheath were removed, and the material was rehomogenized in a glass-Teflon homogenizer. The homogenate was diluted to $5 \mathrm{ml}$ with homogenization buffer and centrifuged at $1000 \mathrm{~g}$ for $2 \mathrm{~min}$ to remove any particulate material. All processing of membranes was at $0-4^{\circ} \mathrm{C}$.

\section{PERFUSED MEMBRANE AC ASSAYS}

Continuous assay of AC activity stimulated with transient exposures to $5-\mathrm{HT}$ and $\mathrm{Ca}^{2+}$ was done using the perfused membrane method of Yovell et al. (1987), as modified by Yovell and Abrams (1992), in which neural membranes are retained on a low-density fibrous filter and perfused with assay solution containing $\left[\alpha^{32} \mathrm{P}\right] \mathrm{ATP}$. Upstream from the filter, a valve with five input ports gated by computer-controlled solenoids (General Valve no. 9-453-900, internal volume of 6 $\mu \mathrm{l})$ enabled switching of the incoming solution from among three assay solutions: (1) low $\mathrm{Ca}^{2+}$, (2) high $\mathrm{Ca}^{2+}$, and (3) low $\mathrm{Ca}^{2+}$ with $20 \mu$ M 5-HT. A fourth input port enabled washing with $6 \mathrm{ml}$ of unlabeled low $\mathrm{Ca}^{2+}$ assay solution immediately before the start of an assay to equilibrate membranes and to remove any residual cytosol or free membranes. Assay solution was drawn at $2.5 \mathrm{ml} / \mathrm{min}$ by a peristaltic pump downstream from the filter and collected in 6-sec fractions in tubes containing 100 $\mu \mathrm{l}$ of assay stop solution (Salomon 1979). Assay solutions contained $50 \mathrm{~mm} \mathrm{K-HEPES} \mathrm{(pH} \mathrm{7.6),} 75$ mм KCl, 1 mм DTT, $10 \mu$ м $\left[\alpha{ }^{32} \mathrm{P}\right]$ ATP $(-25 \mu \mathrm{Ci} /$ $\mathrm{ml}), 50 \mu \mathrm{M}\left[{ }^{3} \mathrm{H}\right] \mathrm{cAMP}\left(5 \times 10^{4} \mathrm{cpm} / \mathrm{ml}\right.$, for normalization of column recovery and fraction volume), 1 $\mu$ M CaM, $10 \mu$ м GTP (unless otherwise noted), protease inhibitors (described above), and one of two $\mathrm{Ca}^{2+} / \mathrm{Mg}^{2+} /$ EGTA buffers. EGTA was $3.0 \mathrm{~mm}$ in both low and high $\mathrm{Ca}^{2+}$ assay solutions; total $\mathrm{Ca}^{2+}$ was $25 \mu \mathrm{m}$ in the low $\mathrm{Ca}^{2+}$ assay solution and 4.5 $\mathrm{mM}$ in the high $\mathrm{Ca}^{2+}$ assay solution (i.e., the $\mathrm{Ca}^{2+}$ pulse solution); and total $\mathrm{Mg}^{2+}$ was $1.45 \mathrm{~mm}$ in the low $\mathrm{Ca}^{2+}$ solution and $1.0 \mathrm{~mm}$ in the high $\mathrm{Ca}^{2+}$ solution. Free $\mathrm{Mg}^{2+}$ was $1 \mathrm{~mm}$ in both solutions. Free $\mathrm{Ca}^{2+}$ in the low $\mathrm{Ca}^{2+}$ solution was $<1 \mathrm{~nm}$. During a 6-sec "pulse," the maximum solution change is $\sim 80 \%$; thus, free $\mathrm{Ca}^{2+}$ transiently reached $-600 \mu \mathrm{M}$; during a 6-sec pulse of 5-HT, the peak 5-HT concentration reached $\sim 16 \mu \mathrm{M}$ (Fig. 1A). In some experiments, $0.5 \mathrm{~mm}$ IBMX was included in the assay solution. However, the phosphodiesterase inhibitor did not affect cAMP recovery; this may reflect either effective protection of synthesized cAMP by the $50 \mu \mathrm{M}$ CAMP present in the assay solution or the low level of phosphodiesterase remaining in the membranes.

In each experiment, $25 \%$ of the homogenate from six CNSs was injected onto a prewet, $10-\mathrm{mm}$ diam., borosilicate glass filter (Millipore \#AP25); a separate filter was used for each of four 2-min assays. Cytosol was immediately removed by highpressure washing with $20 \mathrm{ml}$ of ice-cold buffer before connecting the filter to the valve. All comparisons, either of $\mathrm{Ca}^{2+}$-before-5-HT pairing versus 5HT-before- $\mathrm{Ca}^{2+}$ pairing or of decay of AC stimulation with and without a late $\mathrm{Ca}^{2+}$ pulse, were made within preparations; in each preparation, the two conditions were both assayed in duplicate in a counterbalanced A-B-B-A sequence. Because the magnitude of stimulation by $5-\mathrm{HT}$ and $\mathrm{Ca}^{2+}$ pulses varies among preparations, it was critical to make all comparisons within experiments. $\mathrm{AC}$ stimulation by $\mathrm{Ca}^{2+}$ alone that is shown in Figures 4 and 5 (below) was assayed with and without GTP in the same preparations.

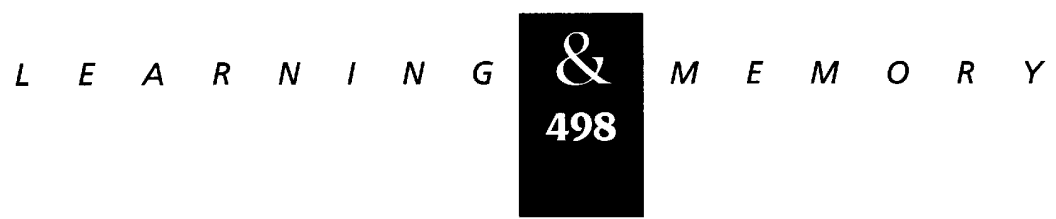



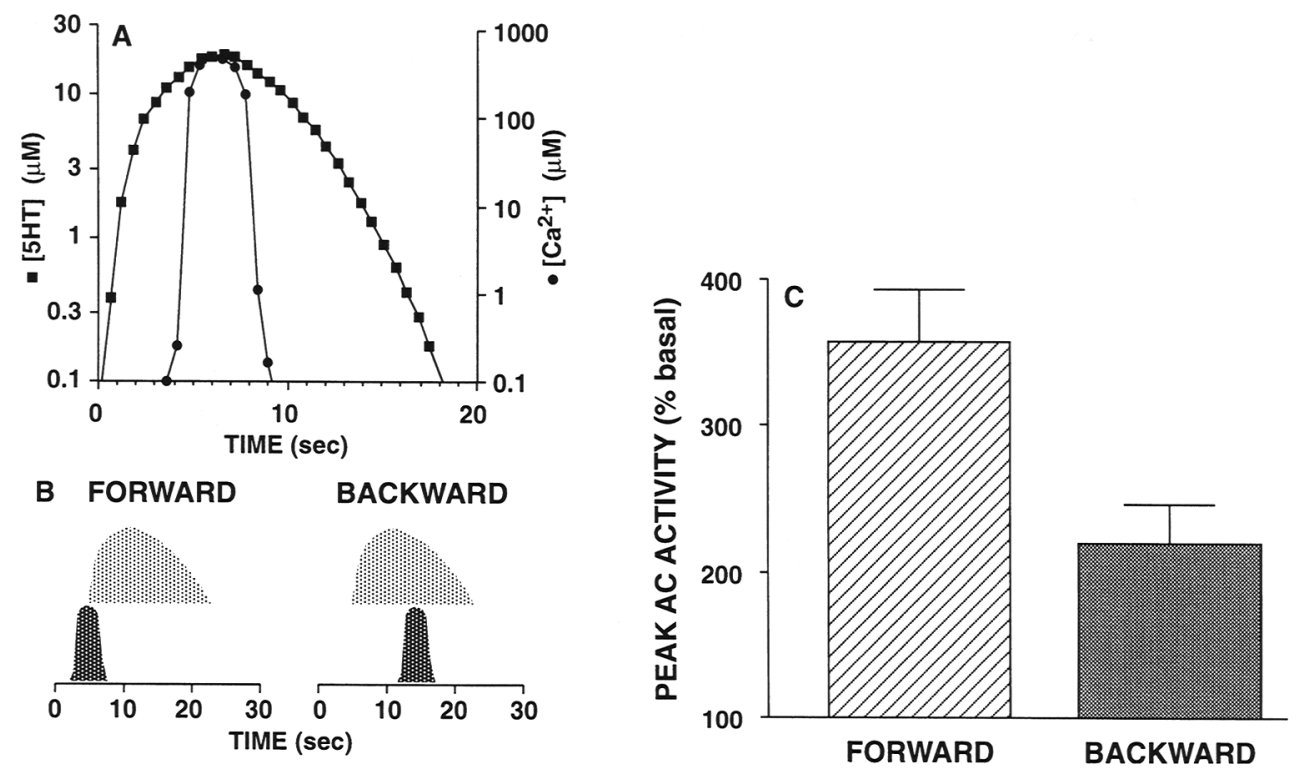

Figure 1: Responses of $\mathrm{AC}$ in perfused Aplysia neural membranes to forward or backward pairing of $\mathrm{Ca}^{2+}$ and $5-\mathrm{HT}$ pulses. (A) Profiles of 5-HT and $\mathrm{Ca}^{2+}$ pulses in perfused membrane experiments. Concentration of 5-HT in the neural membranes during and after a 6 -sec $5-\mathrm{HT}$ pulse $(\boldsymbol{\square})$ was calculated from measurements of the time course of solution change (which was determined with a radioactivity detector flow cell immediately downstream from the filter and ${ }^{32} \mathrm{P}$ in the stimulus solution). Free $\mathrm{Ca}^{2+}$ concentration during and after a 6 -sec $\mathrm{Ca}^{2+}$ pulse $(\mathbf{O})$ calculated from measurements of the time course of solution change. The narrower $\mathrm{Ca}^{2+}$ stimulus profile is a consequence of $\mathrm{Ca}^{2+}$ chelation by the EGTA in the low $\mathrm{Ca}^{2+}$ assay solution. Note that $12 \mathrm{sec}$ after the termination of perfusion with $5-\mathrm{HT}$, free 5 -HT at the membranes had dropped below $100 \mathrm{~nm}$, a level that would not have produced measurable AC stimulation in these assays. $(B)$ Temporal relationship of $\mathrm{Ca}^{2+}$ and 5-HT stimuli when paired in forward and backward sequences. Profiles of $\mathrm{Ca}^{2+}(\mathrm{dark}$ stippled area) and 5-HT (light stippled area) are from $A$. With forward pairing, a 6-sec $\mathrm{Ca}^{2+}$ pulse was given immediately before a 6-sec 5-HT pulse; with backward pairing, the 6-sec $\mathrm{Ca}^{2+}$ pulse was given immediately following the 6-sec 5-HT pulse. Thus, in both sequences when the valve controlling one stimulus solution was switched off, the valve controlling the second stimulus solution was switched on. The overlapping temporal profiles of the two stimuli result from the fact that ligand concentration increased and decreased gradually within the filter chamber. (C) AC stimulation with paired $\mathrm{Ca}^{2+}$ and 5-HT pulses in forward $\left(\mathrm{Ca}^{2+}\right.$ followed by $\left.5-\mathrm{HT}\right)$ and backward $\left(5-\mathrm{HT}\right.$ followed by $\mathrm{Ca}^{2+}$ ) sequences. Peak AC activity during response to paired $\mathrm{Ca}^{2+}$ and 5-HT pulses is expressed as percent of basal AC activity. AC activity was determined by collecting perfusate during consecutive 6 -sec intervals and determining ${ }^{32}$ P-labeled cAMP synthesized from [ $\left.\alpha{ }^{32} \mathrm{P}\right] A T P$. The difference between peak stimulation with forward and backward pairing was highly consistent and significant within preparations $(P<0.001$, two-tailed paired $t$-test; $n=6)$; moreover, the profiles of stimulation over time were significantly different $F(9,45)=17.2, P<0.001$ ). (Because both basal activity and AC stimulation vary substantially among preparations, all comparisons are made within preparations. Each stimulus condition in this and subsequent figures was assayed in duplicate on each preparation.)

ESTIMATES OF TIME COURSE OF EXPOSURE TO 5-HT AND $\mathrm{Ca}^{2+}$

Although the valve had an internal volume of $<6 \mu$ and produced a relatively square pulse of $\mathrm{Ca}^{2+}$ or $5-\mathrm{HT}$, the filter itself contained $\sim 100 \mu \mathrm{l}$ of solution; thus, with the flow rate used, the ligand concentration increased and decreased gradually at the membranes. To determine the rate of solution change, the ratio of two solutions during and after a pulse was measured with radioactivity detector flow cell immediately downstream from the filter chamber and ${ }^{32} \mathrm{P}$ in one of the solutions. The 5-HT concentration during and after a pulse of transmitter is directly proportional to the ratio of assay solutions with and without transmitter at the membranes (Fig. 1A). The free $\mathrm{Ca}^{2+}$ concentration during and after a $\mathrm{Ca}^{2+}$ pulse (Fig. 1A) was calculated from the rate of solution change data and the concentrations of EGTA, $\mathrm{Ca}^{2+}$ and $\mathrm{Mg}^{2+}$ in the high and low $\mathrm{Ca}^{2+}$ solutions, by using an iterative computer program and published association constants for $\mathrm{Ca}^{2+}-$ EGTA, $\mathrm{Mg}^{2+}$-EGTA, and $\mathrm{H}^{+}$-EGTA (Blinks et al. 1 982).

$$
\begin{array}{lllllllllllllll}
\hline & E & A & R & N & I & N & G & \mathbf{Q} & M & E & M & O & R & Y \\
499 & & & & & &
\end{array}
$$


Abrams et al.

Figure 2: $\mathrm{Ca}^{2+}$ and 5-HT produce less than additive stimulation of AC. AC activity was assayed in Aplysia neural membranes under steady-state conditions with a range of concentrations of $5-\mathrm{HT}$, from $100 \mathrm{nM}$ to $100 \mu \mathrm{M}$, in either $10 \mathrm{nM}$ or $1.5 \mu \mathrm{M}$ free $\mathrm{Ca}^{2+}$ with $1 \mu \mathrm{M}$ CaM. (A) AC activity expressed as percent of $A C$ basal activity $[(O)$ with $5-\mathrm{HT}$; (O) with $\left.5-\mathrm{HT}+\mathrm{Ca}^{2+}\right]$. (B) $\mathrm{Ca}^{2+}$ stimulation vs. 5 -HT concentration. $\mathrm{Ca}^{2+}$ stimulation is expressed as either percent of basal AC activity as in $A(\boldsymbol{\square})$ or as per-
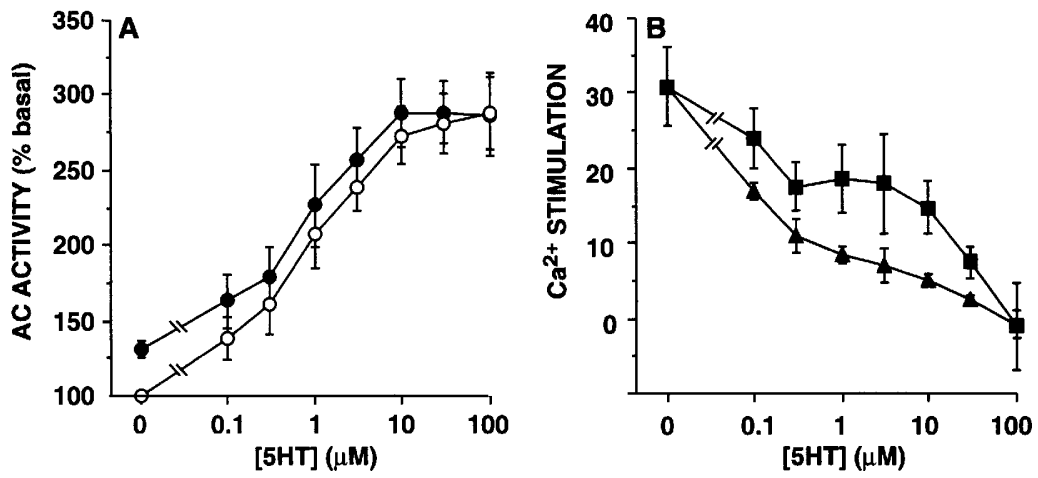

cent of AC activity in low $\mathrm{Ca}^{2+}$ with the same concentration of 5-HT( $\left.\mathbf{\Delta}\right)$. Note, as 5-HT stimulation of AC increases, net $\mathrm{Ca}^{2+}$ stimulation decreases. As suggested in Discussion, this reduction in $\mathrm{Ca}^{2+}$ stimulation may actually represent a decrease in GTP stimulation caused by $\mathrm{Ca}^{2+} / \mathrm{CaM}$.

\section{DATA ANALYSIS}

Statistical analysis of peak AC stimulation or of total cAMP synthesis was done with within-preparation comparisons and a paired $t$-test. Comparisons of profiles of AC stimulation over time were done with a repeated measures ANOVA with 2 within-preparation factors (treatment and time) testing treatment $\times$ time interactions. Rate constants for decay of AC stimulation were estimated by fitting exponential functions to the falling phase of data with Igor software (Wavemetrics, Lake Oswego, OR). All data are presented as mean \pm s.E.M.

\section{Results}

FORWARD VS. BACKWARD AC STIMULATION WITH BRIEFER 5-HT AND $\mathrm{Ca}^{2+}$ STIMULI

To better study the effect of $\mathrm{Ca}^{2+} / \mathrm{CaM}$ on 5HT activation of AC by transient transmitter stimuli, we improved the flow characteristics of the chamber that houses the filter with the neural membranes and reduced the diameter of the filter; the 5-HT pulse now terminated more rapidly, without the long tail present in previous experiments (Fig. 1A) (Yovell and Abrams 1992). As in the previous study (Yovell and Abrams 1992), activation of $\mathrm{AC}$ in perfused neural membranes was substantially greater when a $\mathrm{Ca}^{2+}$ pulse immediately preceded the 5-HT pulse (forward pairing) than when $\mathrm{Ca}^{2+}$ immediately followed the transmitter pulse (backward pairing) (Fig. 1C) (peak stimulation above basal $=263 \pm 32 \%$ vs. $129 \pm 3 \%, P<0.001$; these and all other data are expressed as mean \pm S.E.M.). Because of differences of several- fold in both basal activity and amount of transmitter stimulation among groups of animals, all comparisons are made within experiments (see Materials and Methods). In the present experiments, because the improved rate of solution change, the $\mathrm{Ca}^{2+}$ pulse reached a substantially higher peak level $(\sim 600 \mu \mathrm{M})$ than in previous experiments $(0.3-$ $10 \mu \mathrm{M}$ ) (Yovell and Abrams 1992). Thus, the sequence preference of $\mathrm{AC}$ for $\mathrm{Ca}^{2+}$ preceding 5-HT is relatively insensitive to the precise peak level of free $\mathrm{Ca}^{2+}$ during a pulse.

\section{LACK OF SYNERGISTIC INTERACTIONS BETWEEN $\mathrm{Ca}^{2+}$ AND TRANSMITTER IN ACTIVATING AC WHEN EXPOSURES TO THE TWO STIMULI ARE CONTINUOUS OR SIMULTANOUS}

Yovell and Abrams (1992) had reported a lack of synergism when $\mathrm{Ca}^{2+} / \mathrm{CaM}$ and 5-HT are paired in steady-state assays in which both stimuli are present for the duration of the assay. In experiments in which a range of 5-HT concentrations were tested with or without stimulatory $\mathrm{Ca}^{2+}$, we now observed that at maximally effective concentrations of $5-\mathrm{HT}$, the stimulatory effect of $\mathrm{Ca}^{2+} / \mathrm{CaM}$ actually disappeared. Thus, $30 \mu \mathrm{M} 5-\mathrm{HT}$ plus $\mathrm{Ca}^{2+}$ produced no greater activation of Aplysia neural AC than $30 \mu \mathrm{m}$ 5-HT alone (Fig. 2A). Indeed, absolute stimulation by $\mathrm{Ca}^{2+}$ decreased in a graded manner as the concentration of 5-HT increased (Fig. 2B). [Less-than-additive stimulation by 5-HT plus $\mathrm{Ca}^{2+}$ was present in the earlier results of Yovell and Abrams (1992) although it was not considered to be a real effect because of limited data.] This lack of enhancement of 5-HT stimulation of AC was also observed when transient $\mathrm{Ca}^{2+}$ and 5-HT stimuli 
were given simultaneously or with substantial overlap; for example, in one series of experiments, simultaneous onset did not produce significantly different peak AC stimulation as compared with backward pairing $[415 \pm 28 \%$ vs. $392 \pm 29 \%$, peak stimulation as percent of basal, $n=6$ (L. Lee, unpubl.)].

THE RESPONSE OF APLYSIA NEURAL AC TO A $\mathrm{Ca}^{2+}$ TRANSIENT IS DELAYED, OCCURRING AFTER $\mathrm{Ca}^{2+}$ HAS DECLINED

One reason that simultaneous transient $\mathrm{Ca}^{2+}$ and 5-HT stimuli may not show effective synergism is that the response to $\mathrm{Ca}^{2+}$ pulse is actually delayed. Figure 3 compares the time course of the responses to separate 6-sec $\mathrm{Ca}^{2+}$ and 5-HT pulses.

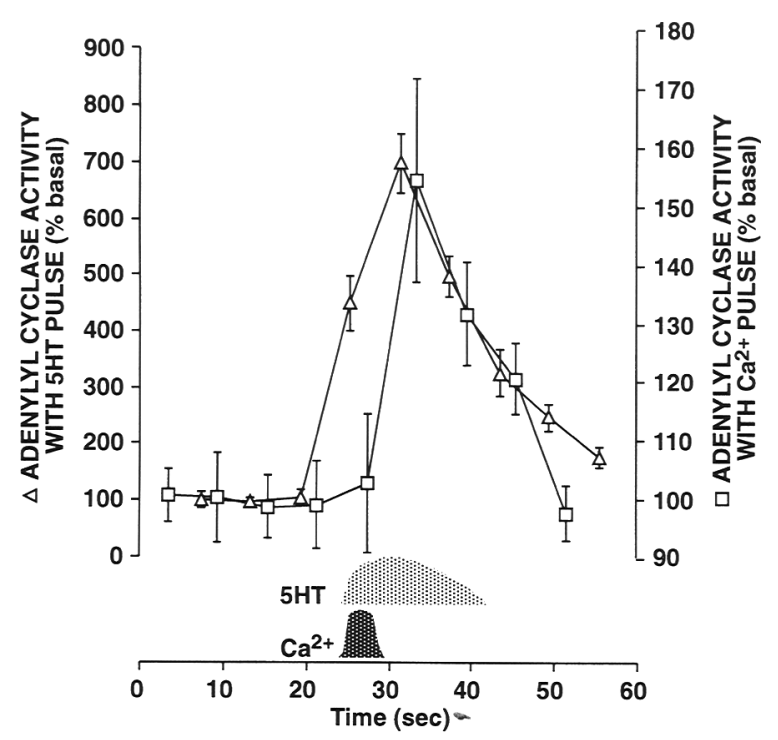

Figure 3: Time course of activation of Aplysia neural $\mathrm{AC}$ by a 6 -sec pulse of either $\mathrm{Ca}^{2+}$ or $5-\mathrm{HT}$. To allow comparison of the time courses of the responses, different vertical axes were used for the two stimuli; thus, stimulation with the $\mathrm{Ca}^{2+}$ pulse $(\square)$ was much smaller than with the 5 -HT pulse $(\triangle): 1.54 \pm 0.17$-fold $(n=6)$ vs. $6.01 \pm 0.56$-fold $(n=3)$. At its peak the $\mathrm{Ca}^{2+}$ pulse (dark stippled area) reached $600 \mu \mathrm{M}$, and the $5-\mathrm{HT}$ pulse (light stippled area) reached $16 \mu \mathrm{M}$. To facilitate comparison of the rising phase of the two responses, we have aligned the two sets of data so that the effective onsets of the two stimuli coincide in the graph (in contrast, in Fig. $1 \mathrm{~A}$, it is evident that after the beginning of a pulse, $\mathrm{Ca}^{2+}$ actually rises more slowly than 5-HT). (Because the magnitude of $5-\mathrm{HT}$ and $\mathrm{Ca}^{2+}$ stimulation varies among preparations, the level of peak activation should not be compared across experiments.)
Because there is no reliable stimulation by a $\mathrm{Ca}^{2+}$ pulse in the presence of GTP, the $\mathrm{Ca}^{2+}$ responses were measured in the absence of GTP. Under these conditions, the 5-HT stimulation rose earlier than the $\mathrm{Ca}^{2+}$ stimulation. Because the 6-sec fraction duration, over which cAMP synthesis is integrated, limits the temporal resolution of these experiments, it is not possible to determine precisely the delay between the peaks of the responses. However, given that the interval in which stimulation first appeared was two fractions earlier with 5-HT than with $\mathrm{Ca}^{2+}$ (Fig. 3) and given the difference between the rising phases of the stimuli in Figure $1 \mathrm{~A}$, there must be a temporal shift of at least $2.7 \mathrm{sec}$ in the onset of the two responses. The peaks of the two responses appear to be shifted by $\sim 1.9 \mathrm{sec}$ (Fig. 3); this estimate, though, has substantial uncertainty because of the fraction size. In another series of experiments, we studied the response to steps of $\mathrm{Ca}^{2+}$ and 5-HT. The onset of stimulation by the 5-HT step occurred significantly earlier than the initial stimulation by the $\mathrm{Ca}^{2+}$ step $(P<0.01$, $n=9$, two-tailed $t$-test). A comparison of the rising phase of the responses to these steps suggested that $50 \%$ activation with 5 -HT occurred $\sim 1.0 \mathrm{sec}$ earlier than $50 \%$ activation by $\mathrm{Ca}^{2+}$ (data not shown). In summary, these results indicate that 5HT stimulation rises faster than $\mathrm{Ca}^{2+} / \mathrm{CaM}$ stimulation of AC. Although little or no $\mathrm{Ca}^{2+}$ stimulation is detectable in the presence of GTP, we suggest that the relevant modulatory effect of $\mathrm{Ca}^{2+} / \mathrm{CaM}$ on the activation of $A C$ by receptor- $G_{s}$ (which ocurs in the presence of GTP) is likely to occur with the same time course as the $\mathrm{Ca}^{2+} / \mathrm{CaM}$ stimulation (characterized here in the absence of GTP) (see Discussion).

\section{A LATE $\mathrm{Ca}^{2+}$ PULSE ACCELERATES THE DECAY OF AC ACTIVATION}

On the basis of several lines of evidence, Yovell and Abrams (1992) proposed that a prepulse of $\mathrm{Ca}^{2+}$ may accelerate the rate of $\mathrm{AC}$ activation by a pulse of 5-HT. However, direct determination of the effect of $\mathrm{Ca}^{2+}$ on the rate of $\mathrm{AC}$ activation proved difficult, primarily because the time course of activation was rapid compared with the temporal resolution of the perfused membrane assay (Yovell and Abrams 1992). If elevated $\mathrm{Ca}^{2+}$ increases the rate of receptor- $\mathrm{G}_{\mathrm{s}}$ activation of $\mathrm{AC}$, we hypothesized that it might also accelerate the decay of $\mathrm{AC}$ activation when the transmitter pulse

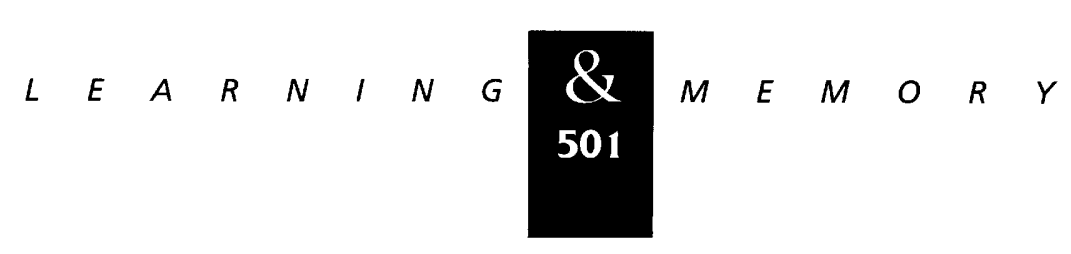


Abrams et al.

ends. Consistent with this possibility, the difference between pairing with $\mathrm{Ca}^{2+}$-before-5-HT and pairing with 5-HT-before- $\mathrm{Ca}^{2+}$ tended to be greater than the difference between pairing with $\mathrm{Ca}^{2+}$-before-5-HT and a 5-HT pulse alone (Yovell and Abrams 1992). To independently test the hypothesis that $\mathrm{Ca}^{2+} / \mathrm{CaM}$ binding influences the rate of receptor- $\mathrm{G}_{\mathrm{s}}$ interactions with $\mathrm{AC}$, we examined the effects of a late $\mathrm{Ca}^{2+}$ pulse on the decay phase of AC stimulation by a 5-HT pulse. Because the decay phase of 5-HT activation is substantially slower than the rising phase, it is possible to more accurately determine changes in the decay of activation.

To separate effects of $\mathrm{Ca}^{2+}$ on peak AC activation from effects on the decay of activation, the $\mathrm{Ca}^{2+}$ pulse was delivered after 5-HT available to the membranes had decreased below the threshold concentration for stimulating AC (Figs. 1A, 2, and 4). The $\mathrm{Ca}^{2+}$ exposure began $\sim 4$ sec after 5 -HT dropped below $100 \mathrm{~nm}$, which was $<0.6 \%$ of the peak concentration during the transmitter pulse; $100 \mathrm{~nm}$ 5-HT is the minimal concentration for detectable stimulation of AC in Aplysia neural membranes (Jarrard et al. 1993; Fig. 2) and one order of magnitude lower than the $\mathrm{EC}_{50}$ for the AC-coupled 5-HT receptor (J.E. Cohen and T.W. Abrams, unpubl.). The decay of 5-HT stimulation could be measured more accurately than previously possible because the reduced volume of the valve and filter; we were now able to observe some persistent $\mathrm{AC}$ activation after 5-HT elimination, which had not been detected by Yovell et al. (1987). In the absence of a late $\mathrm{Ca}^{2+}$ pulse, $\mathrm{AC}$ activation decayed to basal levels $\sim 1 \mathrm{~min}$ after free 5 -HT was washed from the membranes. Consistent with the prediction that $\mathrm{Ca}^{2+}$ would accelerate the decay of $\mathrm{AC}$ activation by receptor- $G_{s}$, we found that the decay of 5-HT stimulation was substantially faster when a pulse of $\mathrm{Ca}^{2+}$ was given after 5-HT washout (Fig.
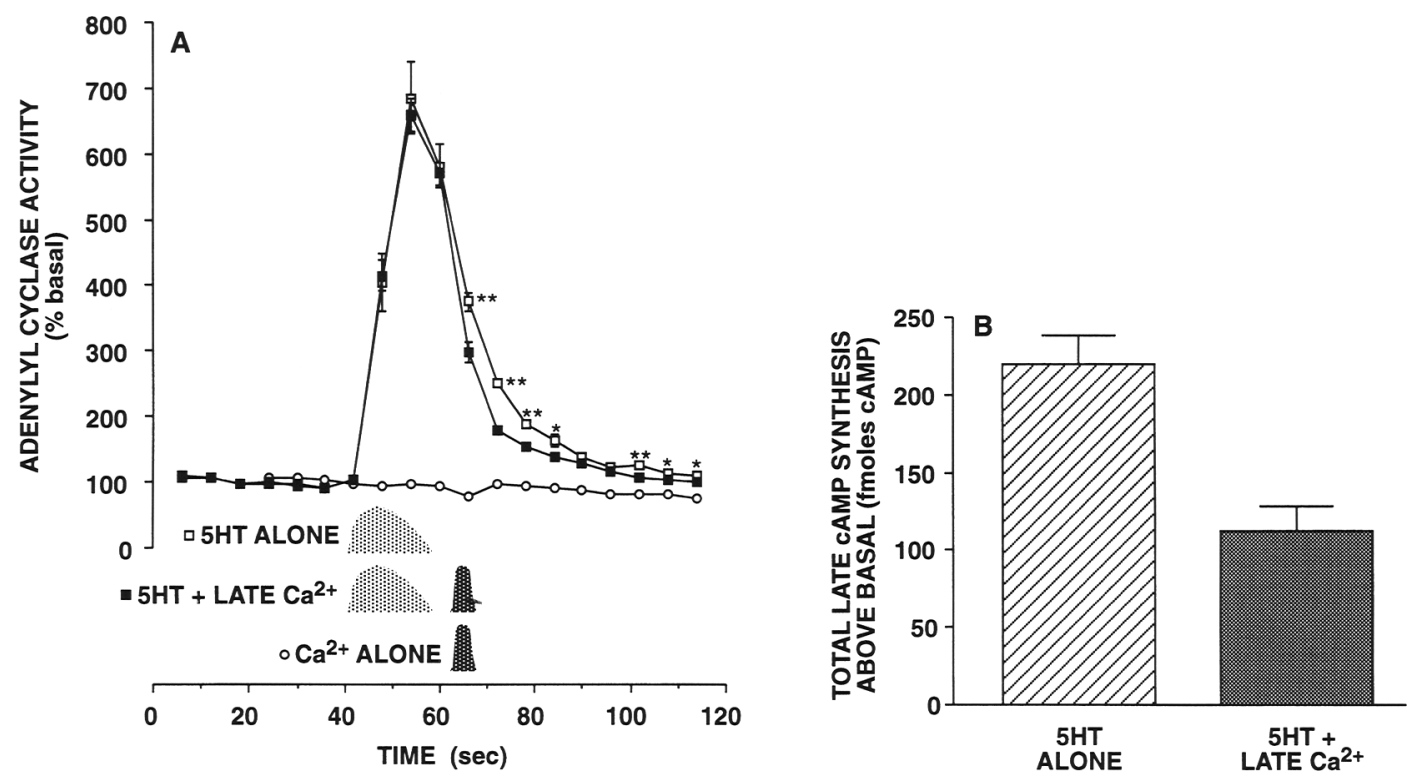

Figure 4: Effect of a late $\mathrm{Ca}^{2+}$ pulse on the decay of AC stimulation after 5-HT exposure. (A) A 6-sec 5-HT pulse was delivered either alone $(\square)$ or followed by a $\mathrm{Ca}^{2+}$ pulse $(\boldsymbol{\square})$. The profiles below show timing of 5 -HT (light stippled area) and $\mathrm{Ca}^{2+}$ (dark stippled area) exposures. Perfusion with the high $\mathrm{Ca}^{2+}$ assay solution began $12 \mathrm{sec}$ after the 5-HT pulse was terminated; the $\mathrm{Ca}^{2+}$ concentration rose into a stimulatory range $\sim 4 \mathrm{sec}$ later. $\mathrm{Ca}^{2+}$ alone $(O)$ is the response to the same $\mathrm{Ca}^{2+}$ pulse (in the presence of GTP) without prior exposure to $5-\mathrm{HT}(n=6)$. AC activity during each 6 -sec interval is expressed as percent of basal activity. Note that AC activity throughout the decaying phase of 5-HT stimulation was significantly decreased by the brief $\mathrm{Ca}^{2+}$ pulse $\left.F(8,40)=10.6, P<0.001\right)$. Whereas $\mathrm{Ca}^{2+}$ alone has a transient inhibitory effect, this reduction in activity lasted only during the $\mathrm{Ca}^{2+}$ pulse and therefore cannot directly account for the sustained reduction in $\mathrm{AC}$ activity produced by the $\mathrm{Ca}^{2+}$ pulse after a $5-\mathrm{HT}$ exposure. $5-\mathrm{HT}$ and $\mathrm{Ca}^{2+}$ buffer concentrations were as in Fig. 1. [Error bars (S.E.M.) are frequently smaller than symbols.] (B) Total stimulation of cAMP synthesis after washout of $5-\mathrm{HT}$, with and without a late $\mathrm{Ca}^{2+}$ pulse. To emphasize the overall effect of the late $\mathrm{Ca}^{2+}$ pulse on cAMP synthesis during the decay phase of stimulation, the total stimulated synthesis of cAMP (minus basal synthesis) is plotted from the time of onset of the $\mathrm{Ca}^{2+}$ pulse. Data from experiments in $A$.

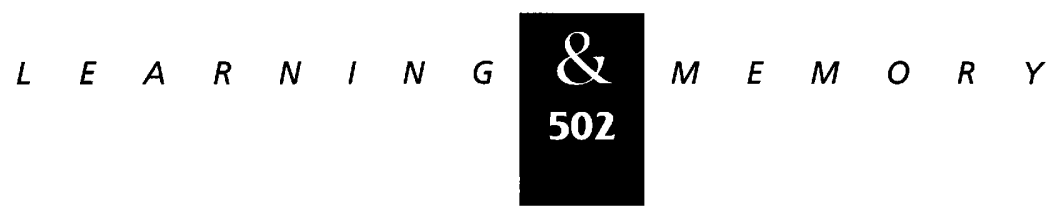


4A). In the first 6 sec after 5-HT was eliminated, AC stimulation declined $49.6 \pm 1.6 \%$ when a late $\mathrm{Ca}^{2+}$ pulse was given as compared with a decrease of $35.8 \pm 1.8 \%$ without a $\mathrm{Ca}^{2+}$ pulse (the overall decay phase of the stimulation was significantly altered by the $\mathrm{Ca}^{2+}$ pulse; $F(8,40)=10.6, P<0.001$, $n=6$; repeated measures ANOVA testing the treatment $x$ time interaction). In the two 6-sec fractions during which the $\mathrm{Ca}^{2+}$ elevation occurred, the rate constant for decay of AC stimulation increased significantly (from $0.098 \pm 0.004$ / sec with 5 -HT alone to $0.170 \pm 0.007 / \mathrm{sec}$ with a late $\mathrm{Ca}^{2+}$ pulse; $P<0.002$, two-tailed paired $t$-test). This effect on the decay rate of AC activation was transient; by the first 6-sec fraction after free $\mathrm{Ca}^{2+}$ had declined, the decay rate was no longer increased. Although the acceleration of the decay rate occurs only during the $\mathrm{Ca}^{2+}$ pulse, its consequences are longer lasting. The decrease in $\mathrm{AC}$ activity with a late $\mathrm{Ca}^{2+}$ pulse compared with 5-HT alone remained significant until the activity had decayed to near basal levels, that is, $>30 \mathrm{sec}$ (Fig. 4A). Thus, $\mathrm{Ca}^{2+}$ appears to accelerate the decay of AC activation by 5 -HT, rather than producing transient inhibition. In the absence of GTP, this same $\mathrm{Ca}^{2+}$ pulse was stimulatory, producing peak stimulation of $54 \pm 17 \%$ above basal (Fig. 3). In contrast, in the presence of GTP, the $\mathrm{Ca}^{2+}$ pulse alone produced a transient decrease in AC activity (Fig. 4, $\mathrm{Ca}^{2+}$ ALONE); this brief effect cannot account quantitatively for the long-duration effect on the decaying phase of 5-HT stimulation, which is evident well after $\mathrm{Ca}^{2+}$ disappears. (The reason for the switch in the direction of the transient $\mathrm{Ca}^{2+}$ effect when GTP is present is considered in Discussion.)

Yovell and Abrams (1992) had found that the difference between forward versus backward pairing could be reduced or eliminated by omitting exogenous CaM. [It is often not possible to entirely eliminate CaM-mediated effects by omitting exogenous CaM because neural membranes contain appreciable endogenous CaM that is difficult to remove completely (Eliot et al. 1989).] In two experiments, we examined the effect of $\mathrm{Ca}^{2+}$ on the decay phase of 5-HT stimulation in the absence of exogenous CaM. Although the late $\mathrm{Ca}^{2+}$ pulse still accelerated the decay of 5-HT stimulation, the decay rate during the $\mathrm{Ca}^{2+}$ pulse (mean rate constant $=0.118 \pm 0.014 / \mathrm{sec}$ ) was significantly less than in the presence of exogenous CaM $(P<0.05$, two-tailed $t$-test), suggesting that the acceleration in decay rate is mediated via CaM.

Although compared with the peak of 5-HT stimulation, this effect of a brief $\mathrm{Ca}^{2+}$ pulse on $\mathrm{AC}$ activity during the prolonged decaying phase of stimulation appears modest (Fig. 4A), it could well be physiologically significant. In Figure $4 \mathrm{~B}$, we compare the integral of total stimulated cAMP synthesis over the 54-sec period in the decaying phase from the time the $\mathrm{Ca}^{2+}$ exposure occurs; the brief $\mathrm{Ca}^{2+}$ pulse resulted in a 1.96 -fold reduction in total stimulated cAMP synthesis during this late phase of the response.

\section{EFFECT OF THE $\mathrm{Ca}^{2+}$ PULSE ON G-INDEPENDENT ACTIVATION OF AC BY FORSOLIN}

If the acceleration by $\mathrm{Ca}^{2+}$ of the decay of $\mathrm{AC}$ activation is due to modulation of receptor- $G_{s}$ interactions with $\mathrm{AC}$, there should not be a $\mathrm{Ca}^{2+}$. dependent increase in the rate of decay of activation of AC with compounds such as forskolin (Seamon and Daly 1986) that stimulate AC directly, rather than via $G_{s}$. To test this prediction, we substituted for 5-HT a pulse of the water-soluble forskolin analog deacetyl- $N$-methyl-piperazino-butyryl forskolin (dampb-Forsk). $\mathrm{A} \mathrm{Ca}^{2+}$ pulse delivered after dampb-Forsk washout did not accelerate the decay of AC activation but instead produced synergistic stimulation of AC, compared with a $\mathrm{Ca}^{2+}$ pulse alone (in the absence of GTP) (Fig. 5). These assays with dampb-Forsk were conducted in the absence of GTP to allow direct comparison with the stimulation that can be measured by a $\mathrm{Ca}^{2+}$ pulse in the absence of GTP. We also conducted similar experiments with a dampb-Forsk pulse in the presence of GTP. Although the stimulation (as a percent of basal activity) by dampb-Forsk was substantially less than in the absence of GTP, the stimulation profiles were qualitatively the same: A peak of $\mathrm{Ca}^{2+}$ stimulation sat superimposed on the falling phase of dampb-Forsk stimulation, and the two stimuli activated AC synergistically (data not shown).

\section{Discussion}

In a number of experimental systems, associative interactions between stimuli within the CNS have been found to occur at the level of dually regulated molecules (Bourne and Nicoll 1993). In Aplysia sensory neurons, the dually regulated $\mathrm{Ca}^{2+} / \mathrm{CaM}$-sensitive AC provides one site of associative convergence between $\mathrm{Ca}^{2+}$ influx and facili-

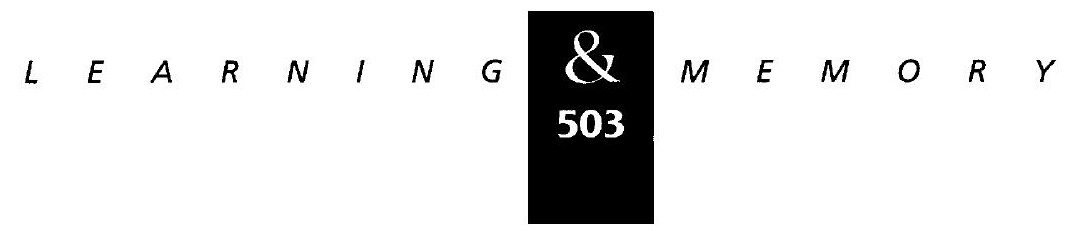


Abrams et al.

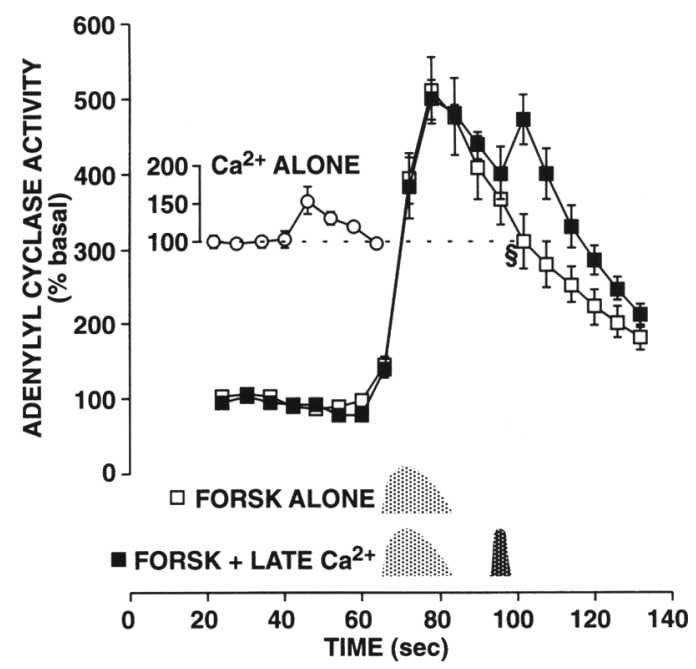

Figure 5: Effect of a late $\mathrm{Ca}^{2+}$ pulse on the decay of $\mathrm{AC}$ stimulation after dampb-Forsk exposure. (A) A 6-sec pulse of $100 \mu \mathrm{M}$ dampb-Forsk was delivered either alone $(\square)$ or followed by a $\mathrm{Ca}^{2+}$ pulse $(\mathbf{\square})(n=4)$. Perfusion with the high $\mathrm{Ca}^{2+}$ assay solution began $18 \mathrm{sec}$ after the dampb-Forsk pulse was terminated. $\mathrm{Ca}^{2+}$ alone $(O)$ is the response to this same $\mathrm{Ca}^{2+}$ pulse, in assays without GTP, plotted on the same scale axes (data are from Fig. 3) $(n=6)$. To enable comparison, the $\mathrm{Ca}^{2+}$ alone graph is shifted vertically so that basal activity $(100 \%)$ aligns with the dampb-Forsk alone response at the time of the $\mathrm{Ca}^{2+}$ pulse (indicated by $\S$ and the broken line). Note that the late $\mathrm{Ca}^{2+}$ pulse during the decaying phase of the forskolin response did not accelerate the decay but rather activated AC synergistically. (It is difficult to compare stimulation across experiments; however, the $\mathrm{Ca}^{2+}$ stimulation during the forskolin response was $162 \%$ of basal, calculated by subtracting the activity at the same time point in the forskolin response without $\mathrm{Ca}^{2+}$, which is more than twofold greater than has been seen with $\mathrm{Ca}^{2+}$ pulses alone.) A longer delay was used between the dampb-Forsk and $\mathrm{Ca}^{2+}$ pulses than with the 5-HT pulse (Fig. 4) because the forskolin response decays more slowly than the 5-HT response. Data for dampb-Forsk and dampb-Forsk plus late $\mathrm{Ca}^{2+}$ are from experiments on four preparations; data for $\mathrm{Ca}^{2+}$ alone without GTP were obtained in the same six preparations in which responses to $\mathrm{Ca}^{2+}$ pulses alone with GTP were studied (shown in Fig. 4). No GTP was present in the dampb-Forsk experiment assay solutions. [Error bars (S.E.M.) may be smaller than symbols.]

tatory transmitter. During conditioning of the defensive withdrawal response, these two cellular stimuli are triggered by the CS and US, respectively. Consistent with the proposal that convergence at this molecular site plays an important role in initiating neural plasticity during conditioning,
Aplysia neural AC shows a sequence preference analogous to the CS-US sequence requirement of conditioning: $\mathrm{Ca}^{2+}$ preceding transmitter produces more powerful activation than $\mathrm{Ca}^{2+}$ following transmitter (Fig. 1; Yovell and Abrams 1992).

The difference between forward and backward pairing of $\mathrm{Ca}^{2+}$ and 5-HT has now been observed with the peak $\mathrm{Ca}^{2+}$ concentration during the pulse ranging from $<1 \mu \mathrm{M}$ to $600 \mu \mathrm{M}$ (Fig. 1; Yovell and Abrams 1992). Thus, the sequence preference of AC occurs over a wide range of peak $\mathrm{Ca}^{2+}$ levels, though the forward versus backward difference was somewhat greater with larger $\mathrm{Ca}^{2+}$ pulses. This sensitivity to $\mathrm{Ca}^{2+}$ is in part a reflection of the $\mathrm{Ca}^{2+}$ affinity of $\mathrm{CaM}$, in the micromolar range (Maune et al. 1992); however, because CaM concentrations are relatively high, both in these assays and in the cell, only a small percentage of CaM needs to bind $\mathrm{Ca}^{2+}$ for $\mathrm{AC}$ to be modulated J.E. Galun, C.U. Onyike, and T.W. Abrams, in prep.; Tang et al. 1991). In neurons, $\mathrm{Ca}^{2+}$ levels at regions of influx can very briefly approach $1 \mathrm{~mm}$ during an action potential (Adler et al. 1991; Roberts et al. 1991; Llinas et al. 1992; Heidelberger et al. 1994); in contrast, shortly after a series of action potentials, $\mathrm{Ca}^{2+}$ levels remain elevated in the range of hundreds of nм (e.g., Blumenfeld et al. 1990). Our data suggest that forward pairing would produce more effective AC activation than backward pairing over a broad range of increases in free $\mathrm{Ca}^{2+}$ levels beneath the membrane of neurons, both during and shortly after a train of action potentials.

ACCELERATION OF THE DECAY OF TRANSMITTER STIMULATION BY A LATE $\mathrm{Ca}^{2+}$ PULSE IS OWING TO MODULATION OF AC ACTIVATION BY $\mathrm{G}_{\mathrm{s}}$ RATHER THAN TO A DIRECT INHIBITORY EFFECT OF $\mathrm{Ca}^{2+}$

Yovell and Abrams (1992) observed that forward pairing increased the initial activation of AC by transmitter compared with both 5-HT alone and backward pairing. They proposed that CaM binding to $\mathrm{AC}$ might accelerate the rate of $\mathrm{AC}$ activation by receptor- $\mathrm{G}_{\mathrm{s}}$, which would have the consequence of increasing the peak AC stimulation achieved when transmitter is present only briefly. We further hypothesized that CaM binding might increase the rates of transition in both directions between the activated and deactivated forms of the $\mathrm{G}_{\mathrm{s}}-\mathrm{AC}$ complex. Thus, if $\mathrm{Ca}^{2+} / \mathrm{CaM}$ were bound to AC when a 5-HT exposure terminated, the rate of 
decay of activated AC might be accelerated. We tested this prediction and observed that $\mathrm{a} \mathrm{Ca}^{2+}$ pulse arriving after 5-HT washout produced a decrease in AC activity during the period in which activation persisted (Fig. 4).

It is important to distinguish whether this decrease in AC activity represents an acceleration of the decay of 5-HT stimulation or simply $\mathrm{Ca}^{2+}$ inhibition of AC. $\mathrm{Ca}^{2+}$ has a biphasic effect on CaMsensitive $\mathrm{AC}$; intermediate levels of $\mathrm{Ca}^{2+}$ stimulate AC activity, via $\mathrm{CaM}$, and high levels of $\mathrm{Ca}^{2+}$ directly inhibit $\mathrm{AC}$, independent of CaM (Brostrom et al. 1977; Yovell et al. 1992; Wu et al. 1993). Several observations suggest that the difference in the decay phase because of a late $\mathrm{Ca}^{2+}$ pulse does not result from direct inhibition of $\mathrm{AC}$ : (1) When the same $\mathrm{Ca}^{2+}$ pulse was delivered in the absence of GTP and transmitter, stimulation was observed, rather than inhibition (Fig. 3); thus, the $\mathrm{Ca}^{2+}$ pulse used must not have been large enough to produce net inhibition of $\mathrm{AC}$. (2) When a late $\mathrm{Ca}^{2+}$ pulse was given following a pulse of dampb-Forsk (which, unlike transmitter, directly activates AC, independently of $\mathrm{G}_{\mathrm{s}}$ ), $\mathrm{Ca}^{2+}$ stimulation interacted synergistically with the decaying phase of the dampb-Forsk response, with no evidence of inhibition. (3) Typically, when CaM is absent and a $\mathrm{Ca}^{2+}$ pulse produces direct $\mathrm{AC}$ inhibition, the effect is transient, occurring in only one or two 6-sec fractions (J.E. Galun, C.U. Onyike, and T.W. Abrams, in prep.). In contrast, the late $\mathrm{Ca}^{2+}$ pulse reduced AC activity for as long as the 5-HT stimulation persisted. Thus, this $\mathrm{Ca}^{2+}$ effect appears to decrease the residual 5-HT stimulation after the transmitter has been removed from the membranes and is no longer available to reactivate the enzyme. In summary, these results suggest that a late increase in $\mathrm{Ca}^{2+}$ after the disappearance of 5$\mathrm{HT}$ accelerates the loss of the residual AC activation.

If the $\mathrm{Ca}^{2+}$ pulse does not have a direct inhibitory effect on AC, why in the presence of GTP did this same pulse result in a transient decrease in AC activity (Fig. 4, $\mathrm{Ca}^{2+}$ ALONE)? In Aplysia neural membranes, exposure to GTP alone, in the absence of transmitter, commonly produces a threeto fourfold increase in AC activity, presumably by limited activation of Gs. The transient inhibition of GTP-activated AC by the $\mathrm{Ca}^{2+}$ pulse may be related to the less-than-additive $\mathrm{AC}$ stimulation by $\mathrm{Ca}^{2+}$ plus 5-HT that we observed under steady-state conditions (Fig. 2). We propose that in these steadystate assays, rather than transmitter and $G_{s}$ block- ing $\mathrm{Ca}^{2+}$ stimulation, $\mathrm{Ca}^{2+} / \mathrm{CaM}$ may be producing a modest decrease in the effective activation of AC by $\mathrm{G}_{\mathrm{s}}$. Consistent with this interpretation, when Aplysia AC has been preactivated with 5-HT with the GTP analog GTP $\gamma$ S, which eliminates GTP hydrolysis and $G_{s}$ dissociation from $\mathrm{AC}$, there is no decrease in the activation by $\mathrm{Ca}^{2+} / \mathrm{CaM}$ (Abrams et al. 1991). In the case of the $\mathrm{Ca}^{2+}$ pulse in the presence of GTP, $\mathrm{Ca}^{2+} / \mathrm{CaM}$ may also be acting to decrease AC stimulation by $\mathrm{G}_{\mathrm{s}}$; because GTP is present continuously, after the $\mathrm{Ca}^{2+}$ pulse has ended $\mathrm{G}_{\mathrm{s}}-\mathrm{GTP}$ is able to reactivate $\mathrm{AC}$, restoring the original level of activated AC (Fig. $4, \mathrm{Ca}^{2+}$ ALONE).

A possible mechanism for this proposed $\mathrm{Ca}^{2+} /$ CaM-induced decrease in $A C$ activation by $G_{s}$ emerges from the hypothesis that $\mathrm{CaM}$ alters the rates of transition of the $\mathrm{G}_{\mathrm{s}}-\mathrm{AC}$ complex between the activated and deactivated states. Although the evidence suggests that $\mathrm{Ca}^{2+} / \mathrm{CaM}$ binding increases the rates in both directions, there may be a slightly greater increase in the rate of deactivation. Thus, in the case of both steady-state assays with 5-HT and GTP, and perfused membrane assays with GTP present continuously, $\mathrm{Ca}^{2+} / \mathrm{CaM}$ may shift the equilibrium slightly, decreasing the fraction of $\mathrm{AC}$ molecules in the activated state. Under steady-state conditions with all stimuli constant, such effects of $\mathrm{Ca}^{2+} / \mathrm{CaM}$ on the net activation of $\mathrm{AC}$ are fairly modest. On the other hand, if the amount of activated $G_{s}$ is increasing or decreasing (i.e., when transmitter arrives or disappears), a $\mathrm{Ca}^{2+}$ pulse appears to have a relatively dramatic effect on the rate at which $\mathrm{AC}$ activity changes.

\section{CONSEQUENCES OF THE EFFECT OF LATE $\mathrm{Ca}^{2+}$ FOR ASSOCIATIVE INTEGRATION OF PAIRED STIMULI}

Although the effects of the late $\mathrm{Ca}^{2+}$ pulse on total AC stimulation may appear modest (Fig. 4), they could well be physiologically significant. When activity in Aplysia sensory neurons is paired with facilitatory input, backward pairing produces significant facilitation of synaptic transmission from these cells, although forward pairing is $~ 75 \%$ more effective (Clark et al. 1994). Thus, the differences in AC activation between forward and backward pairing (Fig. 1; Yovell and Abrams 1992) may be sufficient to account for the sequence dependence of synaptic facilitation. The accelerated decay of AC activation with backward pairing (Fig. 4) could contribute substantially to a difference in to-

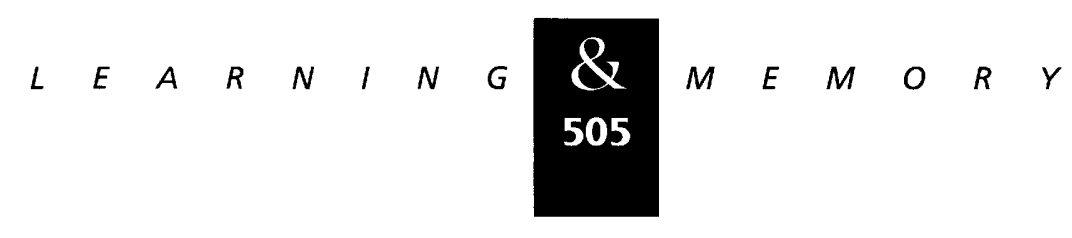


tal cAMP synthesis and, therefore, to the difference in synaptic facilitation between forward and backward pairing.

It is appealing that a single molecular mechanism, a change in the rates of activation and deactivation of $\mathrm{G}_{\mathrm{s}}$-stimulated AC, could both enhance AC stimulation with forward pairing and reduce stimulation with backward pairing; both of these effects would together contribute to a sequence preference where forward pairing is substantially more effective than backward. One expectation would be that behavioral training with backward pairing would be less effective in causing enhancement of subsequent responses to a CS than completely unpaired presentations of the US and CS. Indeed, studies of vertebrate conditioning paradigms have shown that backward presentation of a $\mathrm{CS}$, which at other times is presented before the US, interferes with the animal's learning to recognize this CS as a predictor of the US (Kaplan 1984; Ewing et al. 1985). In the conditioning of the defensive withdrawal reflex of $A p l y s i a$, there is also a small (though not statistically significant) reduction in the response to a backward paired CS compared with an unpaired CS (Hawkins et al. 1986).

\section{DELAYED $\mathrm{Ca}^{2+}$ RESPONSE MAY MAKE SIMULTANEOUS STIMULUS ONSET RELATIVELY INEFFECTIVE}

In most forms of classical conditioning, simultaneous stimulus onset is substantially less effective than forward, CS-US pairing. For example, in conditioning of the rabbit eye-blink reflex, with simultaneous presentations of a tone and an air puff, the animal does not learn to blink to the tone (Smith et al. 1969). Similarly, simultaneous CS and US onset is relatively ineffective in the conditioning of the defensive withdrawal reflex of Aplysia. How might the dually regulated $\mathrm{Ca}^{2+} / \mathrm{CaM}$-sensitive $\mathrm{AC}$ discriminate against simultaneous stimulus onset? We identified a property of AC activation that would cause activation to be more effective if $\mathrm{Ca}^{2+}$ arrived before 5-HT: Activation by $\mathrm{Ca}^{2+} / \mathrm{CaM}$ has a delayed onset (Fig. 3). This delayed activation could account for optimal activation with forward, $\mathrm{Ca}^{2+}$. before-transmitter, pairing if $\mathrm{Ca}^{2+} / \mathrm{CaM}$ effects on $\mathrm{AC}$ activation by $\mathrm{G}_{\mathrm{s}}$ follow the same time course as the $\mathrm{Ca}^{2+} / \mathrm{CaM}$ activation of the enzyme. We have made the assumption that these two effects of $\mathrm{Ca}^{2+} / \mathrm{CaM}, \mathrm{AC}$ stimulation and modulation of receptor-Gs interactions with $\mathrm{AC}$, depend on the same molecular interaction. We believe that this is a reasonable assumption; in the case of the mammalian type I AC, which has been cloned and analyzed in some detail, a single CaM binding site has been identified (Wu et al. 1993).

The relatively crude temporal resolution of the perfused membrane assay, because of the 6-secfraction duration, limits our ability to determine precisely how much the $\mathrm{Ca}^{2+}$ response is delayed compared with the 5-HT response. With $\mathrm{Ca}^{2+}$ and 5-HT pulses, we estimated that peaks of the two responses were shifted by $\sim 1.9 \mathrm{sec}$; our estimate of the shift in the rising phases of the responses to steps of $\mathrm{Ca}^{2+}$ and 5-HT was $\sim 1$ sec. However, as we emphasized, given the limited temporal resolution, these are only estimates of the magnitude of the shift in the two responses. In classical conditioning of the defensive withdrawal reflex, stimulus pairing is most effective when the onset of the CS precedes the onset of the US by $\sim 0.5 \mathrm{sec}$. The temporal shift observed here in the response of $\mathrm{AC}$ to a $\mathrm{Ca}^{2+}$ pulse is undoubtedly severalfold longer. There is, however, also a substantial difference in the duration of the $\mathrm{Ca}^{2+}$ stimulus used in these biochemical assays, $\sim 6 \mathrm{sec}$, and the $\mathrm{Ca}^{2+}$ signals in sensory neurons of the CS pathway during a brief burst of spikes. In behavioral experiments, the weak siphon touch CS probably elicited only a very brief burst of a few spikes in sensory neurons (Illich and Walters, 1997); in electrophysiological studies of associative synaptic facilitation these sensory neurons were activated artificially for only $0.5 \mathrm{sec}$ or less (Hawkins et al. 1983; Walters and Byrne, 1983; Clark et al. 1994). Thus, the $\mathrm{Ca}^{2+}$ signal in the sensory neurons during the CS is probably much briefer than the $\mathrm{Ca}^{2+}$ stimulus used in these assays. This difference in duration could underlie a difference in the optimal delay between the $\mathrm{Ca}^{2+}$ signal and 5-HT stimulus. It is unfortunate that with the present assay system, given the limited level of enzyme activity in Aplysia neural membranes, we can not increase the flow rate to produce briefer solution changes that would more closely approximate the timing of the $\mathrm{Ca}^{2+}$ and 5-HT signals that the sensory neurons experience. Perhaps, this will be possible with another assay system in the future.

Although the $\mathrm{Ca}^{2+} / \mathrm{CaM}$-sensitive $\mathrm{AC}$ is present in mammalian brain where it could play a role in conditioning, there are likely to be multiple molecular mechanisms in the CNS for the formation of associations. In addition to the NMDA receptor and the $\mathrm{Ca}^{2+} / \mathrm{CaM}$-sensitive $\mathrm{AC}$, other molecules in-

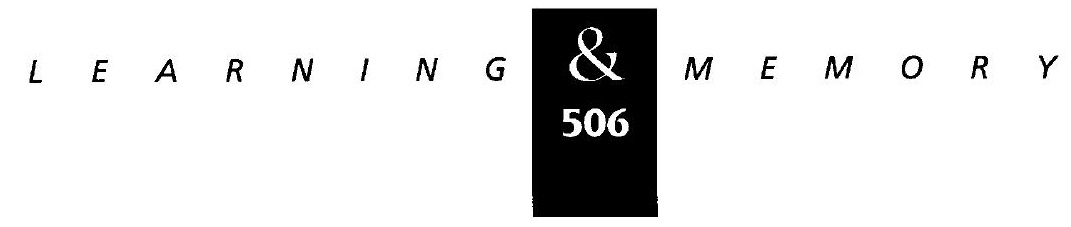


volved in second-messenger cascades may function as convergence sites, gating associative plastic changes (Shibuki and Okada, 1991; Zhuo et al. 1993). Interestingly, other forms of AC may be able to be activated in an associative manner by subunits of multiple $G$ proteins (Tang and Gilman, 1991; Federman et al. 1992). The particular mechanism discussed here in which a $\mathrm{Ca}^{2+}$ prepulse enhances the rate of activation of $\mathrm{AC}$ is probably only important with brief USs. With prolonged USs, activation of $\mathrm{AC}$ would reach a steady-state level even without pairing. However, even with a prolonged $\mathrm{US}, \mathrm{Ca}^{2+}$ modulation of the $\mathrm{G}_{\mathrm{s}}-\mathrm{AC}$ complex might still reduce the efficacy of backward pairing because the decay phase of AC activation would be accelerated.

\section{Acknowledgments}

The experimental results cited were obtained with support from National Institutes of Health grants (NS 25788 and $\mathrm{MH}$ 55880) to T.W.A. We thank Steve Fluharty, David Manning, and Eric Kandel for critically reading and commenting on an earlier version of this manuscript Lawrence Lee provided valuable technical help with the assays. We are grateful to Steve Beuaupre for advising us on the statistical analysis.

The publication costs of this article were defrayed in part by payment of page charges. This article must therefore be hereby marked "advertisement" in accordance with 18 USC section 1734 solely to indicate this fact.

\section{References}

Abrams, T.W. 1985. Activity-dependent presynaptic facilitation: An associative mechanism in Aplysia. Cell. Mol. Neurobiol. 5: 123-145.

Abrams, T.W. and E.R. Kandel. 1988. Is contiguity detection in classical conditioning a system or a cellular property? Learning in Aplysia suggests a possible molecular site. Trends Neurosci. 11: 128-135.

Abrams, T.W., K.A. Karl, and E.R. Kandel. 1991. Biochemical studies of stimulus convergence during classical conditioning in Aplysia: Dual regulation of adenylate cyclase by $\mathrm{Ca}^{2+} /$ calmodulin and transmitter. J. Neurosci.

11: 2655-2665.

Adler, E.M., G.J. Augustine, S.N. Duffy, and M.P. Charlton. 1991. Alien intracellular calcium chelators attenuate neurotransmitter release at the squid giant synapse. J. Neurosci. 11: 1496-1507.

Bao, J.X., E.R. Kandel, and R.D. Hawkins. 1998. Involvement of presynaptic and postsynaptic mechanisms in a cellular analog of classical conditioning at Aplysia sensory-motor neuron synapses in isolated cell culture. J. Neurosci. 18: $458-466$.
Blinks, J.R., W.G. Wier, P. Hess, and F.G. Predergast. 1982. Measurement of $\mathrm{Ca}^{2+}$ concentrations in living cells. Prog. Biophys. Mol. Biol. 40: 1-114.

Blumenfeld, H., M.E. Spira, E.R. Kandel, and S.A. Siegelbaum. 1990. Facilitatory and inhibitory transmitters modulate calcium influx during action potentials in Aplysia sensory neurons. Neuron 5: 487-499.

Bourne, H.R. and R. Nicoll. 1993. Molecular machines integrate coincident synaptic signals. Neuron (Suppl.) 10 65-75.

Braha, O., N. Dale, B. Hochner, M. Klein, T.W. Abrams, and E.R. Kandel. 1990. Second messengers involved in the two processes of presynaptic facilitation that contribute to sensitization and dishabituation in Aplysia sensory neurons. Proc. Natl. Acad. Sci. 87: 2040-2044.

Brostrom, C.O., M.A. Brostrom, and D.J. Wolff. 1977. Calcium-dependent adenylate cyclase from rat cerebral cortex. Reversible activation by sodium fluoride. J. Biol. Chem. 252: 5677-5685.

Brunelli, M., V. Castellucci, and E.R. Kandel. 1976. Synaptic facilitation and behavioral sensitization in Aplysia: Possible role of serotonin and cyclic AMP. Science 194: 1178-1181.

Cali, J.J., J.C. Zwaagstra, N. Mons, D.M. Cooper, and J. Krupinski. 1994. Type VIII adenylyl cyclase. A $\mathrm{Ca}^{2+} /$ calmodulin-stimulated enzyme expressed in discrete regions of rat brain. J. Biol. Chem. 269: 12190-12195.

Clark, G.A., R.D. Hawkins, and E.R. Kandel. 1994. Activity-dependent enhancement of presynaptic facilitation provides a cellular mechanism for the temporal specificity of classical conditioning in Aplysia. Learn. \& Mem. 1: 243-257.

Collingridge, G. 1987. Synaptic plasticity. The role of NMDA receptors in learning and memory. Nature 330: 604-605.

Colwill, R.M., R.A. Absher, and M.L. Roberts. 1988. Context-US learning in Aplysia californica. J. Neurosci. 8: 4434-4439.

Dash, P.K., B. Hochner, and E.R. Kandel. 1990. Injection of the CAMP-responsive element into the nucleus of Aplysia sensory neurons blocks long-term facilitation. Nature 345: 718-721.

Davis, S., S.P. Butcher, and R.G. Morris. 1992. The NMDA receptor antagonist D-2-amino-5-phosphonopentanoate (D-AP5) impairs spatial learning and LTP in vivo at intracerebral concentrations comparable to those that block LTP in vitro. J. Neurosci. 12: 21-34.

Dudai, Y. and S. Zvi. 1984. Adenylate cyclase in the Drosophila memory mutant rutabaga displays an altered $\mathrm{Ca}^{2+}$ sensitivity. Neurosci. Lett. 47: 119-124.

Eliot, L.S., Y. Dudai, E.R. Kandel, and T.W. Abrams. 1989. $\mathrm{Ca}^{2+} /$ calmodulin sensitivity may be common to all forms of

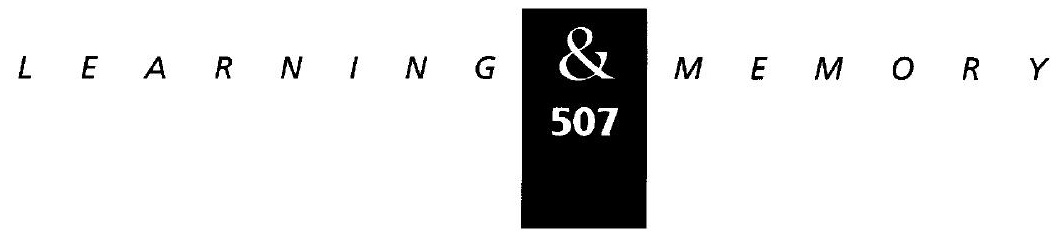


Abrams et al.

neural adenylate cyclase. Proc. Natl. Acad. Sci. 86: 9564-9568.

Ewing, M.F., M.B. Larew, and A.R. Wagner. 1985. Distribution-of-trials effects in Pavlovian conditioning: An apparent involvement of inhibitory backward conditioning with short intertrial intervals. J. Exp. Psychol. Anim. Behav. Processes 11: 537-547.

Federman, A.D., B.R. Conklin, K.A. Schrader, R.R. Reed, and H.R. Bourne. 1992. Hormonal stimulation of adenylyl cyclase through $\mathrm{G}_{\mathrm{i}}$-protein beta gamma subunits. Nature 356: 159-161.

Ghirardi, M., O. Braha, B. Hochner, P.G. Montarolo, E.R. Kandel, and N. Dale. 1992. Roles of PKA and PKC in facilitation of evoked and spontaneous transmitter release at depressed and nondepressed synapses in Aplysia sensory neurons. Neuron 9: 479-489.

Goldsmith, B.A. and T.W. Abrams. 1991. Reversal of synaptic depression by serotonin at Aplysia sensory neuron synapses involves activation of adenylate cyclase. Proc. Natl. Acad. Sci. 88: 9021-9025.

1992. cAMP modulates multiple $\mathrm{K}^{+}$currents increasing spike duration and excitability in Aplysia sensory neurons. Proc. Natl. Acad. Sci. 89: 11481-11485.

Hawkins, R.D., T.W. Abrams, T.J. Carew, and E.R. Kandel. 1983. A cellular mechanism of classical conditioning in Aplysia: Activity-dependent amplification of presynaptic facilitation. Science 219: 400-405.

Hawkins, R.D., T.J. Carew, and E.R. Kandel. 1986. Effects of interstimulus interval and contingency on classical conditioning of the Aplysia siphon withdrawal reflex. ). Neurosci. 6: 1695-1701.

Hearst, E. 1988. Fundamentals of learning and conditioning. In Steven's handbook of experimental psychology (ed. R.C. Atkinson, R.J. Herrnstein, G. Lindzey, and R.D. Luce), pp. 3-109. Wiley Interscience, New York, NY.

Heidelberger, R., C. Heinemann, E. Neher, and G. Matthews. 1994. Calcium dependence of the rate of exocytosis in a synaptic terminal. Nature 371: 513-515.

Hochner, B. and E. Kandel. 1992. Modulation of a transient $\mathrm{K}^{+}$current in the pleural sensory neurons of Aplysia by 5-HT and CAMP: Implications for spike broadening. Proc. Natl. Acad. Sci. 89: 11476-11480.

Illich, P.A. and E.T. Walters. 1997. Mechanosensory neurons innervating Aplysia siphon encode noxious stimuli and display nociceptive sensitization. J. Neurosci. 17: 459-469.

Jarrard, H.E., B.A. Goldsmith, and T.W. Abrams. 1993. In Aplysia sensory neurons, the neuropeptide SCPB and serotonin differ in efficacy both in modulating cellular properties and in activating adenylyl cyclase: Implications for mechanisms underlying presynaptic facilitation. Brain Res. 616: 188-199.
Kaplan, P.S. 1984. Importance of relative temporal parameters in trace autoshaping: From excitation to inhibition. J. Exp. Psychol. Anim. Behav. Processes 10: $113-126$.

Klein, M. 1993. Differential cyclic AMP dependence of facilitation at Aplysia sensorimotor synapses as a function of prior stimulation: Augmentation versus restoration of transmitter release. J. Neurosci. 13: 3793-3801.

Levin, L.R., P.-L. Han, P.M. Hwang, P.G. Feinstein, R.L. Davis, and R.R. Reed. 1992. The Drosophila learning and memory gene rutabaga encodes a $\mathrm{Ca}^{2+} /$ calmodulin-responsive adenylyl cyclase. Cell 68: 479-489.

Livingstone, M.S. 1985. Genetic dissection of Drosophila adenylate cyclase. Proc. Natl. Acad. Sci. 82: 5992-5996.

Livingstone, M.S., P.P. Sziber, and W.G. Quinn. 1984. Loss of calcium/calmodulin responsiveness in adenylate cyclase of rutabaga, a Drosophila learning mutant. Cell 37: 205-215.

Llinas, R., M. Sugimori, and R.B. Silver. 1992. Microdomains of high calcium concentration in a presynaptic terminal. Science 256: 677-679.

Madison, D.V., R.C. Malenka, and R.A. Nicoll. 1991. Mechanisms underlying long-term potentiation of synaptic transmission. Annu. Rev. Neurosci. 14: 379-397.

Maune, J.F., C.B. Klee, and K. Beckingham. 1992. $\mathrm{Ca}^{2+}$ binding and conformational change in two series of point mutations to the individual $\mathrm{Ca}\left({ }^{2+}\right)$-binding sites of calmodulin. J. Biol. Chem. 267: 5286-5295.

Murphy, G.G. and D.L. Glanzman. 1996. Enhancement of sensorimotor connections by conditioning-related stimulation in Aplysia depends upon postsynaptic $\mathrm{Ca}^{2+}$. Proc. Natl. Acad. Sci. 93: 9931-9936.

1997. Mediation of classical conditioning in Aplysia californica by long-term potentiation of sensorimotor synapses. Science 278: 467-471.

Ocorr, K.A., E.T. Walters, and J.H. Byrne. 1985. Associative conditioning analog selectively increases cAMP levels of tail sensory neurons in Aplysia. Proc. Natl. Acad. Sci.

82: 2548-2552.

Rescorla, R.A. 1988. Behavioral studies of Pavlovian conditioning. Annu. Rev. Neurosci. 11: 329-352.

Roberts, W.M., R.A. Jacobs, and A.J. Hudspeth. 1991. The hair cell as a presynaptic terminal. Ann. N.Y. Acad. Sci. 635: $221-233$.

Salomon, Y. 1979. Adenylate cyclase assay. Adv. Cyclic Nucleotide Res.10: 35-55.

Seamon, K.B. and J.W. Daly. 1986. Forskolin: Its biological and chemical properties. Adv. Cyclic Nucleotide Protein Phosphorylation Res. 20: 1-150.

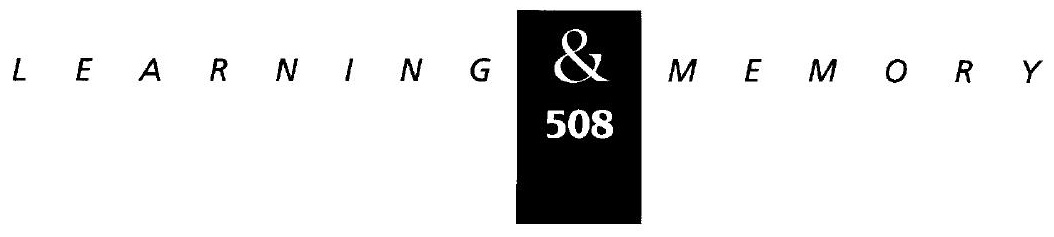


Shibuki, K. and D. Okada. 1991. Endogenous nitric oxide release required for long-term synaptic depression in the cerebellum. Nature 349: 326-328.

Smith, M.C., S.R. Coleman, and I. Gormezano. 1969. Classical conditioning of the rabbit's nictitating membrane response at backward, simultaneous, and forward CS-US intervals. J. Comp. Physiol. Psych. 69: 226-231.

Tang, W.J. and A.G. Gilman. 1991. Type-specific regulation of adenylyl cyclase by $\mathrm{G}$ protein beta gamma subunits. Science 254: 1500-1503.

Tang, W.J., J. Krupinski, and A.G. Gilman. 1991. Expression and characterization of calmodulin-activated (type I) adenylyl cyclase. J. Biol. Chem. 266: 8595-8603.

Tsien, J.Z., P.T. Huerta, and S. Tonegawa. 1996. The essential role of hippocampal CA1 NMDA

receptor-dependent synaptic plasticity in spatial memory [see comments]. Cell 87: 1327-1338.

Vogel, S.S., G.J. Chin, S.M. Mumby, M. Schonberg, and J.H. Schwartz. 1989. G proteins in Aplysia: Biochemical characterization and regional and subcellular distribution. Brain Res. 478: 281-292.

Walters, E.T. and J.H. Byrne. 1983. Associative conditioning of single sensory neurons suggests a cellular mechanism for learning. Science 219: 405-408.

Wu, Z., S.T. Wong, and D.R. Storm. 1993. Modification of the calcium and calmodulin sensitivity of the type I adenyly! cyclase by mutagenesis of its calmodulin binding domain. J. Biol. Chem. 268: 23766-23768.

Wu, Z.L., S.A. Thomas, E.C. Villacres, Z. Xia, M.L. Simmons, C. Chavkin, R.D. Palmiter, and D.R. Storm. 1995. Altered behavior and long-term potentiation in type I adenylyl cyclase mutant mice. Proc. Natl. Acad. Sci.92: 220-224.

Xia, Z.G., C.D. Refsdal, K.M. Merchant, D.M. Dorsa, and D.R. Storm. 1991. Distribution of mRNA for the caimodulin-sensitive adenylate cyclase in rat brain: Expression in areas associated with learning and memory. Neuron 6: 431-443.

Yeager, R.E., W. Heideman, G.B. Rosenberg, and D.R. Storm 1985. Purification of the calmodulin-sensitive adenylate cyclase from bovine cerebral cortex. Biochemistry 24: $3776-3783$.

Yovell, Y. and T.W. Abrams. 1992. Temporal asymmetry in activation of Aplysia adenylyl cyclase may explain properties of conditioning. Proc. Natl. Acad. Sci. 89: 6526-6530.

Yovell, Y., E.R. Kandel, Y. Dudai, and T.W. Abrams. 1987. Biochemical correlates of short-term sensitization in Aplysia: Temporal analysis of adenylate cyclase stimulation in a perfused-membrane preparation. Proc. Natl. Acad. Sci. 84: 9285-9289.

1992. A quantitative study of the $\mathrm{Ca}^{2+} /$ calmodulin sensitivity of adenylyl cyclase in Aplysia, Drosophila, and rat. J. Neurochem. 59: 1736-1744.

Zhuo, M., S.A. Small, E.R. Kandel, and R.D. Hawkins. 1993. Nitric oxide and carbon monoxide produce activity-dependent long-term synaptic enhancement in hippocampus. Science 260: 1946-1950.

Received December 17, 1997; accepted in revised form February 27, 1998.

$$
\begin{array}{lllllllllllllll}
\hline & A & R & N & I & N & G & \mathbf{Q} & M & E & M & O & R & Y
\end{array}
$$




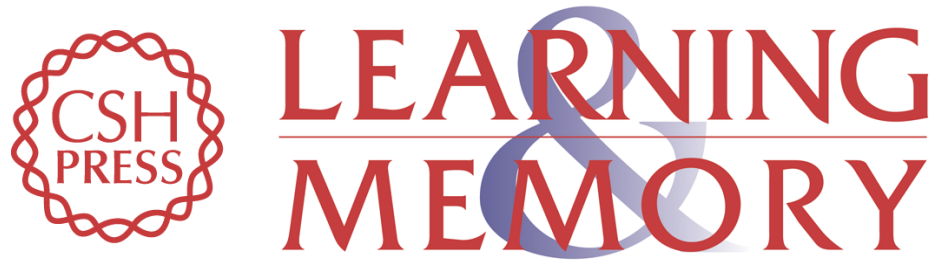

\section{Analysis of sequence-dependent interactions between transient calcium and transmitter stimuli in activating adenylyl cyclase in Aplysia: possible contribution to CS--US sequence requirement during conditioning.}

T W Abrams, Y Yovell, C U Onyike, et al.

Learn. Mem. 1998, 4:

Access the most recent version at doi:10.1101//m.4.6.496

References This article cites 60 articles, 32 of which can be accessed free at:

http://learnmem.cshlp.org/content/4/6/496.full.html\#ref-list-1

License

Email Alerting Receive free email alerts when new articles cite this article - sign up in the box at the Service top right corner of the article or click here. 